\title{
Unsaturated Soil Hydraulic Database of Hungary: HUNSODA
}

\author{
A. NEMES \\ Research Institute for Soil Science and Agricultural Chemistry (RISSAC) of the \\ Hungarian Academy of Sciences, Budapest
}

Protecting soils and water from being damaged by agricultural and industrial pollution is a major concern. Numerical simulation models are increasingly being used to manage agricultural production, to predict the behavior of soil contaminants, and to simulate transport processes in the vadose zone. These models typically require a large variety of input data, in particular, soil hydraulic data. The quality of these inputs often substantially affects the quality of the simulation results (LEIJ \& VAN GENUCHTEN, 1999).

Advances are being made to measure soil hydraulic properties (cf. GEE \& WARD, 1999). Despite these efforts, the unfortunate fact remains that the hydraulic parameters are still always notoriously difficult to measure, especially for undisturbed field soils. The methodology to determine soil water retention, $\theta$ (h), and, especially, the unsaturated hydraulic conductivity, $K(h)$ or $K(\theta)$, is often perceived as inadequate for many applications, especially when a large number of samples are required (WÖSTEN et al., 2001).

An alternative to direct measurement of the unsaturated hydraulic properties is the use and/or generalization of experimental data that are already available. These alternative approaches require reliable sets of soil hydraulic data, as well as basic soil properties (such as soil texture, bulk density, and organic material content) or other information that may have an influence on the hydraulic behavior of soils.

The use of models for research and management has shown that many input data have to be quantified in order to be able to make reliable predictions at regional, national or supra-national scales. Unfortunately, these data are often fragmented, of different degree of detail, of varying reliability and are held in different databases or in different institutes (WÖSTEN et al., 1999). The role and importance of proper national and international scale databases in resolving agricultural and environmental issues is often emphasized (e.g. LEIJ \& VAN GENUCHTEN, 1999). Many electronic databases with soil information exist al-

Correspondence to: Attila NEMES, Research Institute for Soil Science and Agricultural Chemistry (RISSAC) of the Hungarian Academy of Sciences. H-1022 Budapest, Herman Ottó út 15. Hungary. E-mail: bloro@spike.fa.gau.hu 
ready, however, the emphasis of most of the databases is on soil taxonomy and they often have limited unsaturated soil hydraulic data. With soil hydraulic data in focus, the international UNsaturated SOil DAtabase (UNSODA) (LEIJ et al., 1996; NEMES et al., 2001) and the European database of soil hydraulic properties (HYPRES) (WÖSTEN et al., 1999) were developed. Both databases contain a wealth of information on soil hydraulic data, measurement methods and other relevant soil data and have provided data to numerous studies.

Similar soil data have also been collected in Hungary. Many studies took place that used smaller or more extensive datasets of soil hydraulic properties. VÁRALLYAY et al. (1979) described water retention curves by fitting different functions and polynomials to measured data. VÁRALLYAY et al. (1980) established a new categorization system and developed a 1:100 000 scale map of soil water management properties for Hungary. RAJKAI (1984) calculated capillary conductivity of soils using their water retention curves, and compared them with measured data. RAJKAI et al. (1981) calculated water retention data from other - easily measurable - soil physical properties, which techniques were improved later further by RAJKAI and KABOS (1999).

This paper describes a newly developed data source of physical and hydrophysical properties of Hungarian soils. At present, this searchable database holds information on 840 individual soil horizons. The structure and contents of the database are discussed.

\section{The Database}

\section{Database structure}

HUNSODA is a compilation of the available Hungarian soil hydraulic data in Microsoft Access-97 format. MS Access has been chosen because it is widely available and allows management of data on "stand-alone" computers as well as through computer networks. This format provides flexibility in data entry, manipulation and retrieval as well as data output and interfacing with other applications. Furthermore, MS Access has extensive user-friendly query and graphics capabilities for the examination of the database. The database design was kept as general as possible and the user can readily add, delete, edit data or, if desired, modify the database structure.

Data are stored in 8 tables as logical groups of fields. Each of the 840 soil horizons in HUNSODA received a unique identification number that is stored in a separate field named "ID". The numbering begins from 1 and continues with an increment of 1 in the order of data entry. The tables are linked ("indexed") through this field - except the "profiles" table, where this field is not applicable (see later). This ID system is more efficient and error-free while defining relations between tables than via text fields. 
By opening a table in "design view", the structure of each individual table, the name, data type and description of each field in the table can be inspected and modified. Through the design view one can also specify what the default value should be if there are no data for a particular field. Missing data in the database are usually indicated with a "No data" entry.

The structure of the database, names of tables, links between tables as well as the amount of available data for each field are outlined in Figure 1. The two main tables of HUNSODA are called "profiles" and "horizons". The "profiles" table holds basic information about the soil profiles, such as their geographic location, classification and some features of their environment. The soil type is originally given according to the Hungarian classification system (field "local_soiltype"). Later, the FAO soil type was roughly determined from the available information, using the FAO World Reference Base (FAO, 1998) and is given in a separate field ("FAO_soiltype"). Some diagnostic features that were observed or determined at the site using quick tests can also be consulted here. The "horizons" table holds the diagnostic description of all 840 horizons in the database. The horizon notations are given according to the Hungarian soil classification system (STEFANOVITS, 1963; SZABOLCS, 1966). The table can be consulted for information on where the horizon is situated within the profile and on the depth from where the undisturbed sample was taken. Features such as colour, Munsell-colour (Munsell Color Co., 1975), dampness, compaction status, soil structure, presence of plant residues (roots) and the transition into the next horizon are also stored in this table. As every profile (may) have several horizons, it is apparent that the above-described "ID" number cannot link these two tables. A 3-digit unique profile identification number (field "profile_nr") has been introduced to enable a proper link between these tables. Obviously, more horizons have the same "profile_nr" entry in the "horizons" table, but duplicate numbers are not allowed in the "profiles" table to keep unanimous correspondence.

The "soil_properties" table contains laboratory-determined physical and chemical data for each horizon. There are 4 tables that contain data with a functional relation between an independent and a dependent variable. Soil water retention (WR) data are stored as $h-\theta$ curves. The absolute value of the soil matric or pressure head, $h$, is given in $\mathrm{cm}(\mathrm{hPa})$; and the water content, $\theta$, is expressed in $\mathrm{cm}^{3} / \mathrm{cm}^{3}$. WR data are stored in two ways: in a column and in a table format. Table "wrc_columnar" has only three fields: one for the horizon ID number, and two for the actual $h-\theta$ data pairs. Since water contents were always measured at standard pressure head values for these Hungarian soils, the same data are stored in a different way, too. Table "wrc_tabular" stores data in such way, that for each applied pressure-head value, a separate field is allocated. The particle size distribution (PSD) tables store the fraction of soil mass as a function of the particle size or diameter for soil particles smaller than $2 \mathrm{~mm}$ 


\begin{tabular}{|c|c|c|c|c|c|}
\hline \multicolumn{2}{|l|}{ profiles } & \multicolumn{2}{|l|}{ horizons } & \multicolumn{2}{|c|}{ soil_properties } \\
\hline profile_ro & 177 & & 840 & $I D$ & 840 \\
\hline profile nathe & 177 & profile ror & 840 & FAOsand & 725 \\
\hline local soiltwpe & 175 & horizon & 811 & FAOsilt & 725 \\
\hline $\mathrm{FAO}^{-}$soiltype & 0 & total_horizon_tnt & 812 & FAOday & 725 \\
\hline location & 87 & actual_horizoti_tri & 812 & FAOclass & 725 \\
\hline vegetation & 124 & total undistatbed & 840 & USDAclass & 725 \\
\hline relief & 117 & actuas_lundisturbed & 840 & bulk_density & 501 \\
\hline enwir orm ent. & 80 & depth_upper & 824 & particle_density & 440 \\
\hline depth_tor ofile & 125 & depth_lower & 772 & porosity & 437 \\
\hline depth_gwater & 75 & undistutbed_upper & 621 & or Ganic_th aterial & 670 \\
\hline thick hutnius & 112 & undistutbed_lower & 621 & sat_conductivity & 257 \\
\hline quick_carbonate & 123 & colous - & 646 & $\mathrm{Hy}^{-}$ & 81 \\
\hline quick_alkalinity & 59 & colour_Mutisell & 584 & & 410 \\
\hline comments & & datmptiess & 632 & $\mathrm{pH} \_\mathrm{H} 2 \mathrm{O}$ & 692 \\
\hline & & compaction & 603 & $\mathrm{pH} \_\mathrm{KCl}$ & 612 \\
\hline \multirow{2}{*}{\multicolumn{2}{|c|}{ fitted_vanGenuchten }} & roots & 373 & $\mathrm{CaCO3}$ & 684 \\
\hline & & quick_texture & 691 & $\mathrm{KA}$ & 601 \\
\hline \multirow{5}{*}{$\begin{array}{l}\text { ID } \\
\text { thetares } \\
\text { thetasat. } \\
\text { alpha } \\
\text { n } \\
\text { nipoirts } \\
\text { fitting_error }\end{array}$} & 576 & commenterts & 483 & salts & 459 \\
\hline & 376 & transition & 480 & $\mathrm{~T}$ & 232 \\
\hline & 570 & & & & \\
\hline & $\begin{array}{l}576 \\
576\end{array}$ & & & & \\
\hline & 576 & & & & \\
\hline \multicolumn{2}{|c|}{ wrc_columnar* } & \multicolumn{2}{|l|}{ psd_columnar * } & & \\
\hline ID & 576 & & 725 & & \\
\hline & 5711 & partsize & 4826 & & \\
\hline theta & 5711 & fraction & 4826 & & \\
\hline \multicolumn{2}{|l|}{ wrc_tahular* } & psd_tabular * & & & \\
\hline ID & 576 & ID & 725 & & \\
\hline ptoo & 576 & 0.2 & 725 & & \\
\hline $\mathrm{pfl} 4$ & 531 & $2-5$ & 725 & & \\
\hline pif 10 & 576 & $5-10$ & 725 & & \\
\hline pfi 15 & 576 & $10-20$ & 725 & & \\
\hline $\begin{array}{l}\mathrm{pf} 20 \\
\mathrm{pf} 23\end{array}$ & $\begin{array}{l}576 \\
576\end{array}$ & $\begin{array}{l}20-50 \\
50-250\end{array}$ & $\begin{array}{l}725 \\
476\end{array}$ & & \\
\hline $\mathrm{p} 2 \mathrm{~T}$ & 576 & $250-2000$ & 476 & database_d & iption \\
\hline $\mathrm{pf} 34$ & 573 & $50-2000$ & $\begin{array}{l}249 \\
725\end{array}$ & and desct & of all \\
\hline $\begin{array}{l}\mathrm{pf} 42 \\
\mathrm{p} f 62\end{array}$ & $\begin{array}{l}576 \\
575\end{array}$ & $\begin{array}{l}\text { mean_diant eter } \\
\text { sd_theat_diatneter }\end{array}$ & 725 & database objects & \\
\hline
\end{tabular}

Figure 1

The database structure and the available data in HUNSODA. The boxes indicate tables (table names are in bold), which include the fields and the number of samples with available data. Indexed fields (in italics) are used to link the tables as depicted with the lines between the tables. Boxes with dotted borders indicate auxiliary tables

Tables "psd_columnar" and "psd_tabular" store PSD data in the same manner as described for WR data above. Experience shows that storing data in both ways can help the user in executing quick selections using various formats.

Table "fitted_vanGenuchten" contains information derived from measured data. The four-parameter van Genuchten model $\left(\theta_{r}, \theta_{s}, \alpha, n\right)$ (VAN GENUCHTEN, 1980) - as one of the most commonly used parameterized inputs for numerical simulation models - was fitted to the water retention data, using a genetic algorithm that minimizes the fitting error. The four fitted parameters are stored for 
each horizon where water retention data were available. The number of considered water retention data pairs and the error of the fit averaged for the curve were also logged here.

Information on measurement methodology can be found in the "Description" of each field, where applicable. Those can be consulted once the appropriate table is opened in design view.

An auxiliary table is included in HUNSODA. A table titled "database description" provides a summary of the field names, data types and other details of all objects (tables, queries and reports) provided in the database to help the user in familiarizing with the database.

\section{Data}

HUNSODA at present holds information on 840 soil horizons collected by and analyzed at the Research Institute for Soil Science and Agricultural Chemistry of the Hungarian Academy of Sciences (RISSAC) and contributed either by individual scientists or as data collected in the framework of joint research projects. The number of records available for each field in the database can be seen in Figure 1.

The "wrc_columnar" table should be interpreted as follows: the database contains 576 soil samples with water retention data having a total of $5711 \mathrm{~h}-\theta$ data pairs. Figures for the "wrc_tabular" table show how many samples of the database have measured values at the particular pressure-head value. The particle size tables should be interpreted likewise. Figure 2 shows the geographical location of the profiles. Data of these profiles were not specifically collected in the framework of a single major project, so the location of profiles does not reflect any systematic sampling. However, most of the lowland areas that are of major agricultural or environmental interest are represented in the database.

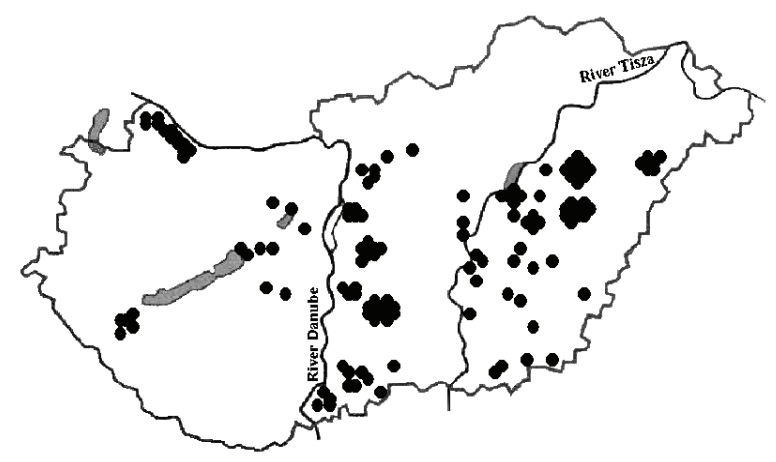

Figure 2

Map of the sampling locations of soils in HUNSODA 
Figure 3 shows the USDA-SCS texture triangle and the distribution of the 725 samples with original measured data. Most of the textural groups are well represented. Soils with very fine texture and those that are a mixture of very fine and coarse particles (sandy clays) are however somewhat underrepresented - which may correspond with the probability of their natural occurrence. Table 1 shows the number of topsoil and subsoil horizons with available water re-

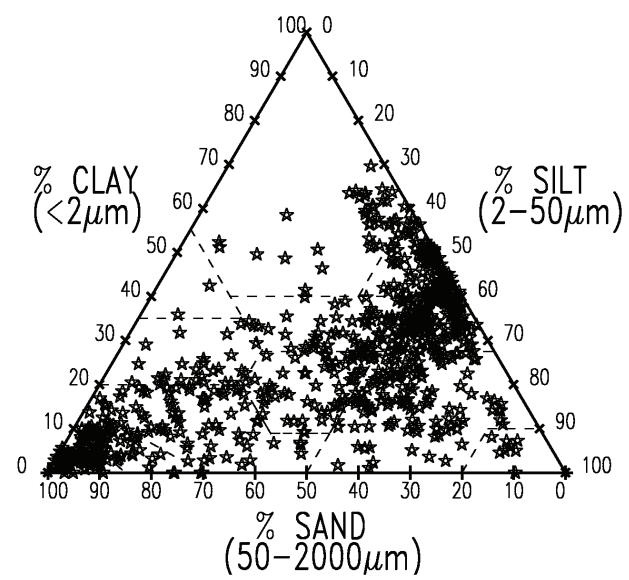

Figure 3

Distribution of soils in HUNSODA across the USDA-SCS soil textural triangle

Table 1

Textural distribution of soils with measured water retention and particle size distribution data in the HUNSODA database according to the FAO classification system and according to the USDA classification system

\begin{tabular}{|c|c|c|c|c|c|c|c|c|c|}
\hline $\begin{array}{l}\text { FAO } \\
\text { class }\end{array}$ & $\begin{array}{l}\text { Sub- } \\
\text { soil }\end{array}$ & $\begin{array}{l}\text { Top- } \\
\text { soil }\end{array}$ & $\mathrm{n}$ & $\begin{array}{c}\% \text { of } \\
N\end{array}$ & $\begin{array}{c}\text { USDA } \\
\text { class }\end{array}$ & $\begin{array}{c}\text { Sub- } \\
\text { soil }\end{array}$ & $\begin{array}{l}\text { Top- } \\
\text { soil }\end{array}$ & $\mathrm{n}$ & $\begin{array}{c}\text { \% of } \\
\mathrm{N}\end{array}$ \\
\hline $\mathrm{C}$ & 49 & 19 & 68 & 12.8 & $\mathrm{~S}$ & 27 & 9 & 36 & 6.8 \\
\hline M & 128 & 78 & 206 & 38.8 & IS & 7 & 6 & 13 & 2.4 \\
\hline MF & 57 & 25 & 82 & 15.4 & $\mathrm{sL}$ & 30 & 11 & 41 & 7.7 \\
\hline $\mathrm{F}$ & 120 & 43 & 163 & 30.7 & $\mathrm{scL}$ & 7 & 2 & 9 & 1.7 \\
\hline VF & 7 & 5 & 12 & 2.3 & C & 18 & 10 & 28 & 5.3 \\
\hline$n$ & 361 & 170 & 531 & & $\mathrm{cL}$ & 23 & 11 & 34 & 6.4 \\
\hline \multirow{7}{*}{$\%$ of $N$} & 68 & 32 & & & $\mathrm{~L}$ & 24 & 21 & 45 & 8.5 \\
\hline & & & & & SiL & 65 & 43 & 108 & 20.3 \\
\hline & & & & & $\mathrm{Si}$ & 6 & 3 & 9 & 1.7 \\
\hline & & & & & sicL & 87 & 34 & 121 & 22.8 \\
\hline & & & & & $\mathrm{siC}$ & 67 & 20 & 87 & 16.4 \\
\hline & & & & & & 361 & 170 & 531 & \\
\hline & & & & & $\%$ of $N$ & 68 & 32 & & \\
\hline
\end{tabular}


tention data in each of the texture classes according to the FAO (FAO, 1995) and USDA (USDA, 1951) classification systems. Any soil horizons which were classified as ' $A$ ' horizons were considered as topsoils, all others were grouped together as subsoils. The poor representation of the 'very fine' group (FAO) is apparent. There are considerably more SiL, siC and sicL soils with available water retention data than soils in other USDA textural classes. Unlike some other databases, HUNSODA does not show bias in favor of coarse-textured soils, which is partly due to the natural occurrence of soil textural types and partly may reflect experimental interests (e.g. salinity research) towards soils with heavier texture. In principle, topsoils represent one third of the database.

There are 576 available water retention curves measured in the laboratory. Water contents were determined at 10 standard pressure-head values which are $0,-2.5,-10,-30,-100,-200,-500,-2500,-15000$ and $-1.5 * 10^{6} \mathrm{hPa}$ (that are equivalent to $\mathrm{pF} 0, \mathrm{pF} 0.4, \mathrm{pF} 1.0, \mathrm{pF} 1.5, \mathrm{pF} 2, \mathrm{pF} 2.3, \mathrm{pF} 2.7, \mathrm{pF} 3.4, \mathrm{pF} 4.2$ and $\mathrm{pF} 6.2)$. Some of the hydraulic data are geometric averages for replicate curves for the same horizon/sample. The available data covers a $40-50 \%(\mathrm{v} / \mathrm{v})$ wide band from 0 to $-15000 \mathrm{hPa}$. The number of points on each water retention curve and the wide range in $\theta$ and $h$ makes the database a suitable data source for the optimization of mathematical expressions or the development of pedotransfer functions.

\section{Database Operations}

The database allows a number of operations such as searching according to user-defined criteria, editing or adding data and extracting or reporting all or selected parts of the database. In the following, we will briefly review these operations.

Specific information can be obtained from the database by running a 'query' to retrieve data from one or more tables according to user-defined criteria. Queries can be specified in SQL (Standard Query Language) or they can be entered through a graphical interface, which does not require detailed knowledge of SQL. Through the graphical interface queries are designed by first selecting the relevant tables, after which the appropriate fields are chosen. These fields are selected either because their values constitute the desired output of the query or because they are used as constraints. Data that conform to the query criteria will appear as output in a table-like structure.

HUNSODA is not write-protected, thus the user is able to modify the contents of the database. Editing data is simply a matter of overwriting the proper fields. When the same changes are desired for a lot (or all) of the entries, considerable effort can be avoided by defining an 'update query' that will search and overwrite the contents of all entries that meet the defined criteria. 
New data can be entered in different ways. One can simply open the targeted table in datasheet view and start typing the new data at the end of the appropriate field(s). If large amounts of data need to be entered, it may be useful to import the data from ASCII or spreadsheet files. Alternatively, one can create a form that includes a selection of fields from one or more tables simultaneously. Forms can display additional information on for example, the required data format or other constraints.

Results from a query and the contents of tables can be extracted in ASCII, spreadsheet, or HTML formats, among others. However, preliminary extraction from the database may not always be necessary as Access allows Visual Basic programming to carry out more complex calculations within the database. Data can also be passed to other programs for further processing using their Visual Basic objects. Alternatively, users can define reports that generate formatted (printable) output based on data selected by queries. One such report is provided that summarizes all available information for each horizon.

\section{Availability of the Database}

HUNSODA currently requires 1.5 Mbytes of disk space ( $\sim .4$ Mbytes when condensed) to store the database. The database can be requested by regular mail (Director's Office, MTA TAKI, Herman Ottó u. 15, H-1022 Budapest, Hungary). The database management software MS Access is available as part of Microsoft Office (Professional Edition) or as a separate program (Microsoft Corporation, P.O. Box 97017, Redmond WA 98073, USA).

\section{Summary and Recommendations}

Databases with information on soils often constitute a basic source of information for studies in production agriculture, environmental engineering, and remote sensing. A new, searchable, relational database of soil physical and hydrophysical properties has been developed for Hungarian soils. The database is stored in MS-Access format. The database is compatible with most of the popular software and can be run on a personal computer as well as on computer networks. It currently stores data of 840 soil horizons, 576 having soil hydraulic data, measured using nationally and internationally accepted standard methodology. An outline of the structure and the contents of HUNSODA, as well as a basic guide to its operation has been given.

Developing this database may enhance the ability of Hungarian soil scientists to address many more environmental issues of concern, however, further expansion of the database is recommended. Additional data can easily be included in the database. Expansion of the database may help in making it more widely applicable. 
Key words: unsaturated soil, water retention, hydraulic conductivity, particle size distribution, Standard Query Language

\section{References}

Food and Agriculture Organization (FAO), 1995. Digital Soil Map of the World and Derived Soil Properties. Version 3.5. Rome, Italy.

Food and Agriculture Organization (FAO), 1998. World Reference Base for Soil Resources. FAO World Soil Resources Report 84. Rome, Italy.

GEE, G. W. \& WARD, A. L., 1999. Innovations in two-phase measurements of soil hydraulic properties. In: Proc. Int. Workshop on Characterization and Measurements of the Hydraulic Properties of Unsaturated Porous Media. (Eds.: VAN GENUCHTEN, M. TH., LEIJ, F. J. \& WU, L.) 241-269. University of California. Riverside, CA, USA.

LeiJ, F. J. \& VAN GenuChten, M. TH., 1999. Characterisation and measurement of the hydraulic properties of unsaturated porous media. In: Proc. Int. Workshop on Characterization and Measurements of the Hydraulic Properties of Unsaturated Porous Media. (Eds.: van Genuchten, M. Th., LeiJ, F. J. \& Wu, L.) 1-12. University of California. Riverside, CA, USA.

LeIJ, F. J. et al., 1996. Unsaturated Soil Hydraulic Database, UNSODA 1.0 User's Manual. Report EPA/600/R-96/095, U.S. Environmental Protection Agency. Ada, Oklahoma.

Munsell Color Company, 1975. Munsell Soil Colour Charts. Munsell Color. Kollmorgan, Maryland, USA.

NEMES, A. et al., 2001. Description of the unsaturated soil hydraulic database UNSODA Version 2.0. J. Hydrol. 251. (3-4) 151-162.

RAJKAI, K., 1984. A method for calculating the capillary conductivity of the soil on the basis of the water retention $(\mathrm{pF})$ curve. (In Hungarian) Agrokémia és Talajtan. 33. $50-62$.

RAJKAI, K. et al., 1981. Calculation of water retention data from the texture and the bulk density of soils. (In Hungarian) Agrokémia és Talajtan. 30. 409-438.

RAJKAI, K. \& KABOS, S., 1999. Estimation of soil water retention characteristics (pF curves) from other soil properties. (In Hungarian) Agrokémia és Talajtan. 48. 1532.

Stefanovits, P., 1963. Soils of Hungary. (In Hungarian) Akadémiai Kiadó. Budapest. Hungary.

SzABOLCS, I. (Ed.) 1966. Methodology for Genetic Soil Mapping at Farm Scale. (In Hungarian) OMMI. Budapest.

United States Department of Agriculture (USDA), 1951. Soil Survey Manual. U.S. Dept. Agriculture Handbook No. 18., Washington, D. C., USA.

VAN GENUChTEN, M. TH., 1980. A closed-form equation for predicting the hydraulic conductivity of unsaturated soils. Soil Sci. Soc. Am. J. 44. 892-898.

VÁRALLYAY, GY. et al., 1979. Mathematical description of water retention curves. (In Hungarian) Agrokémia és Talajtan. 28. 15-38. 
VÁRALlyAY, GY. et al., 1980. Soil water management categories of Hungarian soils and the map of soil water properties (1:100 000). (In Hungarian) Agrokémia és Talajtan. 29. 77-112.

Wösten, J. H. M. et al., 1999. Development and use of a database of hydraulic properties of European soils. Geoderma. 90. 169-185.

WÖsten, J. H. M., PAChePSKY, YA. A. \& RAWLS, W. J., 2001. Pedotransfer functions: bridging the gap between available basic soil data and missing soil hydraulic characteristics. J. Hydrol. 251. (3-4) 123-150. 